\title{
The O-mannosylation and production of recombinant APA (45/47 KDa) protein from Mycobacterium tuberculosis in Streptomyces lividans is affected by culture conditions in shake flasks
}

\author{
Ramsés A Gamboa-Suasnavart 1,2, Norma A Valdez-Cruz², Laura E Cordova-Dávalos², José A Martínez-Sotelo ${ }^{3}$,
} Luis Servín-González², Clara Espitia ${ }^{3}$ and Mauricio A Trujillo-Roldán ${ }^{1,2^{*}}$

\begin{abstract}
Background: The Ala-Pro-rich O-glycoprotein known as the 45/47 kDa or APA antigen from Mycobacterium tuberculosis is an immunodominant adhesin restricted to mycobacterium genus and has been proposed as an alternative candidate to generate a new vaccine against tuberculosis or for diagnosis kits. In this work, the recombinant O-glycoprotein APA was produced by the non-pathogenic filamentous bacteria Streptomyces lividans, evaluating three different culture conditions. This strain is known for its ability to produce heterologous proteins in a shorter time compared to M. tuberculosis.

Results: Three different shake flask geometries were used to provide different shear and oxygenation conditions; and the impact of those conditions on the morphology of S. lividans and the production of rAPA was characterized and evaluated. Small unbranched free filaments and mycelial clumps were found in baffled and coiled shake flasks, but one order of magnitude larger pellets were found in conventional shake flasks. The production of rAPA is around 3 times higher in small mycelia than in larger pellets, most probably due to difficulties in mass transfer inside pellets. Moreover, there are four putative sites of O-mannosylation in native APA, one of which is located at the carboxy-terminal region. The carbohydrate composition of this site was determined for rAPA by mass spectrometry analysis, and was found to contain different glycoforms depending on culture conditions. Up to two mannoses residues were found in cultures carried out in conventional shake flasks, and up to five mannoses residues were determined in coiled and baffled shake flasks.
\end{abstract}

Conclusions: The shear and/or oxygenation parameters determine the bacterial morphology, the productivity, and the O-mannosylation of rAPA in S. lividans. As demonstrated here, culture conditions have to be carefully controlled in order to obtain recombinant O-glycosylated proteins with similar "quality" in bacteria, particularly, if the protein activity depends on the glycosylation pattern. Furthermore, it will be an interesting exercise to determine the effect of shear and oxygen in shake flasks, to obtain evidences that may be useful in scaling-up these processes to bioreactors. Another approach will be using lab-scale bioreactors under well-controlled conditions, and study the impact of those on rAPA productivity and quality.

Keywords: Shake flasks, shear, oxygenation, APA 45/47 kDa, O-mannosylation, Mycobacterium tuberculosis, Streptomyces lividans

\footnotetext{
* Correspondence: maurotru@biomedicas.unam.mx

'Unidad de Bioprocesos, Instituto de Investigaciones Biomédicas, Universidad

Nacional Autónoma de México. AP. 70228, México, D.F., CP. 04510, México

Full list of author information is available at the end of the article
} 


\section{Background}

Mycobacterium tuberculosis is the main bacterial pathogen causing latent infection in more than a third of the world population, and is also developing resistance to virtually every new drug used to treat tuberculosis, resulting recently in a global emergence of extensively drug-resistant tuberculosis [1-3]. At least 41 glycoproteins were identified in culture filtrates of $M$. tuberculosis, and most of them seem to play important roles in M. tuberculosis infection and host immune response [4-6]. Therefore, some of those glycosylated antigens are good candidates for vaccine development and improvement of diagnosis [6-9]. The first described mannosylated protein in Actinomycetes was the Ala-Pro-rich Antigen (also known as 45/ $47 \mathrm{kDa}$ or APA protein) in M. tuberculosis, which is immunodominant [10-12]. The specific role of APA is not clearly defined; however, it is reported as an adhesin [13], as well as an antigen elicitor of lympho-proliferative responses and cytokine production [8]. It is worth of note, that the $\mathrm{T}$ cell response induced by APA is dependent of its glycosylation status specifically of the $O$-mannosylation of four of their threonines [14]. Particularly, Thr277 presents heterogeneity from none to three mannose units in native APA [11]. In addition, none to four mannose units were found in Thr277 of the rAPA produced in S. lividans [15].

Strains of Streptomyces sp. are well known as good producers of extracellular recombinant proteins; these strains also have the ability to glycosylate their own proteins, as well as heterologous proteins [15-22]. Recent studies in genetics and cell biology have revealed analogies between Streptomyces $s p$. and Mycobacterium sp., both belonging to the phylum Actinobacteria [23]. Moreover, S. lividans allows the production, both in shake flasks [15] and in bioreactor [24], of large amounts of glycosylated rAPA suitable for biochemical studies and immunological assays. However, no detailed study of the effect of culture conditions on the productivity and $O$-glycosylation of rAPA has been reported.

On the other hand, probably more than $90 \%$ of submerged cultures for microbial research purposes are performed in shake flasks $[25,26]$. These studies are carried out due to their low cost, simplicity of operation and availability to do many experiments simultaneously $[27,28]$. Almost all the tasks, such as screening of strains, media optimization, strain development, elucidation of metabolic pathways, investigations of process conditions, and evaluation of fundamental growth kinetics are made in these vessels [27]. In shake flasks the momentum and heat transfer is influenced by the geometry of the rotating bulk liquid, that is the contact area between the liquid and the friction area, i.e. the flask inner wall (and indentations in baffled flasks, or the coiled stainless steel spring in flasks) [29]. On the other hand, the mass transfer (mainly oxygen) is influenced by the wet wall exposed to the surrounding air, this is the mass exchange area [29]. Modifications of shake flasks by the introduction of baffles and other enhancements (like stainless steel spring coils) are frequently necessary in order to provide sufficient aeration and shear stress $[25,29,30]$. In S. lividans cultures, coiled and baffled flasks are normally used [30-33], but no detailed study has been done on how the geometry of the flasks can affect recombinant protein production, and its $O$-glycosylation as a function of the morphology of the filamentous bacteria.

The purpose of this study was to evaluate the culture of S. lividans under three different shake flask geometries (conventional Erlenmeyer, baffled and coiled shake flasks, as shown in Figure 1), given different shear and oxygenation conditions, on the morphology of filamentous bacteria, their growth kinetics, and rAPA production and carbohydrate composition at the $\mathrm{C}$-terminus. Furthermore, to our knowledge there are no reports regarding the influence of culture conditions on protein $\mathrm{O}$-glycosylation by bacteria. However, there are some reports indicating modifications in the $\mathrm{N}$-glycosylation pattern in recombinant proteins produced by eukaryotic cells due to variations in culture conditions [34-37].

\section{Results and Discussion}

The effect of three different shear and oxygenation conditions using conventional, baffled and coiled shake flasks (Figure 1) on S. lividans growth, morphology, recombinant APA protein production and $\mathrm{O}$-glycosylation was evaluated. Kinetics of bacterial growth is shown in Figure 2. The final biomass concentration was not affected significantly, being around $3.3 \mathrm{~g} / \mathrm{L}$ dry weight, specifically, $3.5 \pm$ $0.2 \mathrm{~g} / \mathrm{L}$ for coiled flasks and $3.3 \pm 0.1 \mathrm{~g} / \mathrm{L}$ for conventional and baffled flasks. Moreover, the specific growth rate was not significantly different by Tukey HSD Test $(\mathrm{p}=0.05)$ : in coiled shake flasks $0.12 \pm 0.02 \mathrm{~h}^{-1}$, in baffled flasks 0.11 $\pm 0.01 \mathrm{~h}^{-1}$; and in conventional flasks $0.10 \pm 0.02 \mathrm{~h}^{-1}$. Until differences in specific growth rates between baffled (or coiled), and conventional flasks were reported, a lag phase in conventional and baffled flasks were observed and comparing only the growth slopes, similar tendencies can be found [38]. A similar lag phase were observed in this work (figure 1), surely due to a germination of spores delay in conventional shake flasks.

In order to determine the characteristics of mycelial aggregation, samples were taken at $60 \mathrm{~h}$ from each culture and fixed to avoid the loss of morphology. These samples were analyzed by microscopy (Figure 3 ), and the average diameter, area, perimeter, and roundness of each aggregate was determined (Table 1). The largest and roundest pellets, with diameters up to $1.0 \mathrm{~mm}$, were 
A)

B)
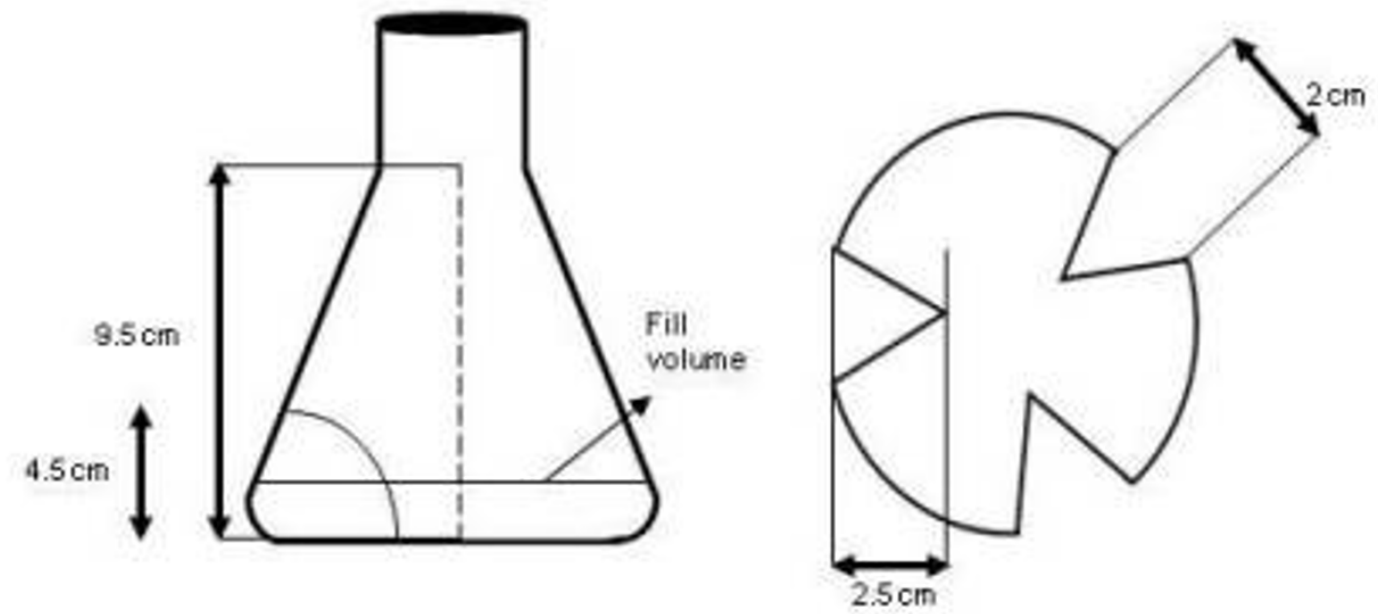

C)

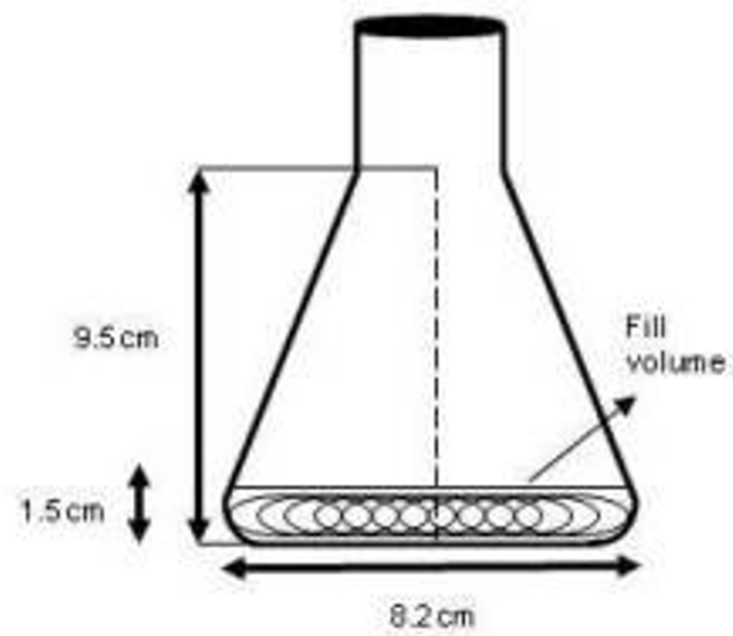

Figure 1 Schematic diagrams of shake flasks used: A. Conventional Normal (NF); B. Baffled (BF); and C. Coiled shake Flasks (CF)

observed in conventional flasks; the smallest clumps, with diameters below $0.25 \mathrm{~mm}$, were obtained in baffled and coiled shake flasks (Table 1, Figure 3). These morphological differences might be attributed to a greater power input/oxygen transfer rate in coiled and baffled shake flasks than in conventional ones. Based on the equations reported by Büchs et al. [39,40], the volumetric power input $(\mathrm{P} / \mathrm{V})$ for conventional shake flasks $(250 \mathrm{ml}$, filled 


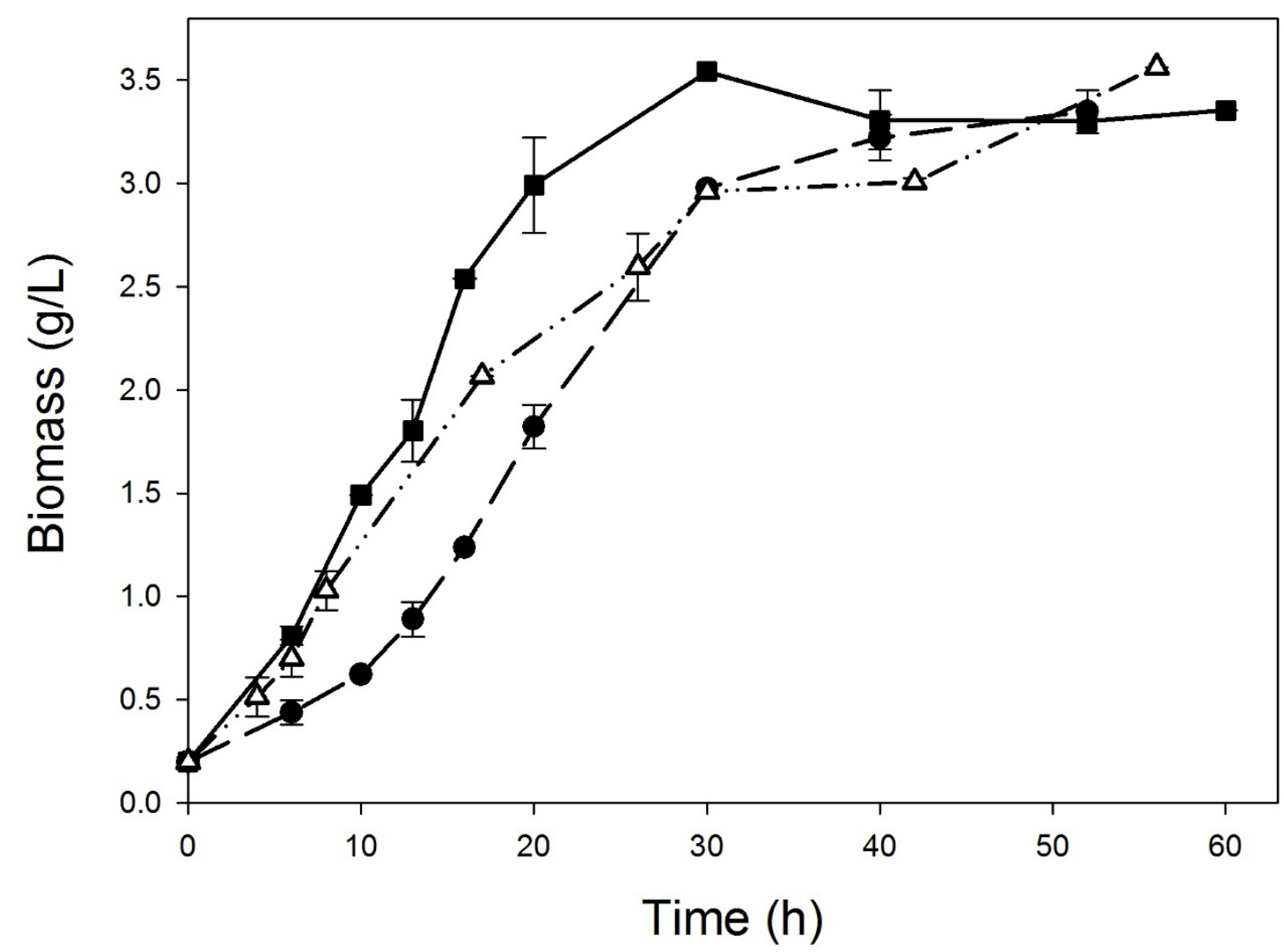

Figure 2 Kinetics of biomass growth of S. lividans producing rAPA from M. tuberculosis, in conventional (squares); baffled (triangles); and coiled (dots) shake flasks.

with $50 \mathrm{ml}$ ), at $150 \mathrm{rpm}$ should be around $0.22 \mathrm{~W} / \mathrm{L}$, but the $\mathrm{P} / \mathrm{V}$ for baffled shake flasks will be more than five times higher, calculated under similar conditions [39-41]. Currently, there are no equations reported for $\mathrm{P} / \mathrm{V}$ in coiled shake flasks. However, since the size on the aggregates is not significantly different in coiled and in baffled flasks, then it would be expected that the power input in coiled flasks should be similar than in baffled flasks. It is worth mentioning that the power input supplied to shake flasks is directly related to the oxygen transfer rate (OTR) $[42,43]$. Then, it can be assumed that the OTR in baffled and coiled flasks is significantly higher than the OTR in conventional shake flasks. Based on the morphology data, between coiled and baffled shake flasks (Table 1 ), it can be assumed that shear and oxygenation conditions are higher in coiled and baffled flasks than in conventional normal flasks.

On the other hand, the larger pellets obtained in conventional flasks have a more rounded shape than the smallest clumps obtained in the other geometries. Although, no porosity measurements were carried out, the pellets can be seen to be very compact, which could bear the thought of nutritional and/or diffusional limitations within them [44], but not critical enough to affect bacterial growth. Manteca et al. [45] observed that the centre of mycelium pellets can contain inactive cells, due to a rapid consumption of substrates (nutrients and/or oxygen) within the kernel of the pellets. However, Yun et al. [38] reported that mass transfer concerns were negligible in S. lividans growth, when pellets reach diameters around $2 \mathrm{~mm}$, at least in terms of oxygen transfer $[38,46]$. Moreover, in S. lividans larger pellets some diffusional limitations might affect the internalization of the inducer, thus reducing recombinant protein production [38], total protein production [38] or the mechanisms involved in post-translational modifications of recombinant proteins $[37,47]$.

\section{Identification and quantification of rAPA produced in three flasks geometries}

The total secreted proteins were analyzed by SDS-PAGE and densitometry, demonstrating that rAPA was produced after induction in all flasks but in different concentrations (Figure 4A). Densitometry analysis shows a higher production of total protein in coiled and in baffled flasks than in conventional flasks (Figure 4A) and confirmed using the BCA Protein Assay Kit obtaining $4.02 \pm 0.08 \mathrm{~g} / \mathrm{L}$ in normal flasks and $7.44 \pm 0.15 \mathrm{~g} / \mathrm{L}$ 


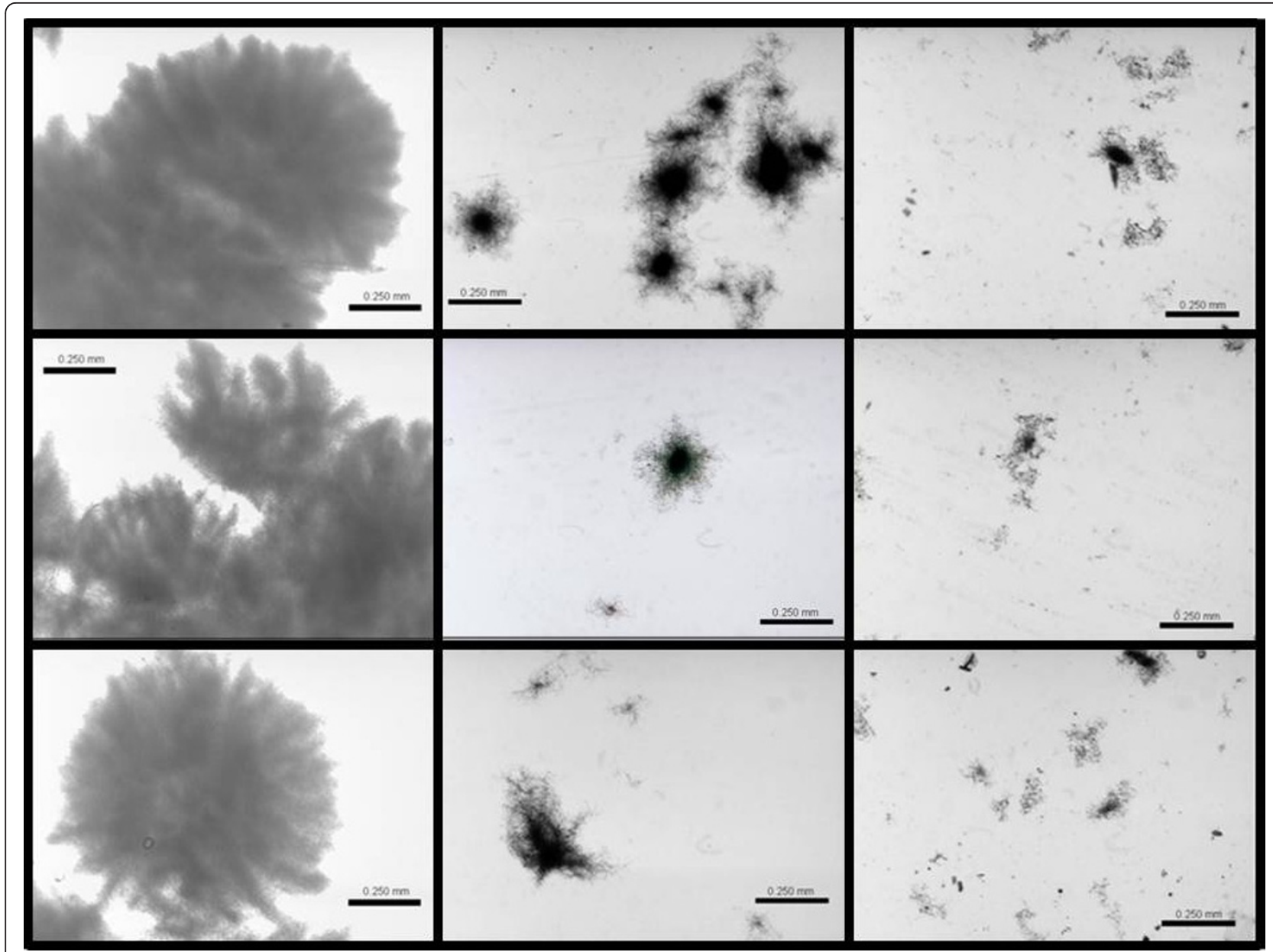

Figure 3 Representative mycelial morphology of S. lividans cultured A. Conventional Normal (NF); B. Baffled (BF); and C. Coiled shake Flasks (CF). (Bar indicates $250 \mu \mathrm{m}, 4 \mathrm{X}$ magnification).

in baffled and coiled flasks. Moreover, two characteristic bands were observed at 45 and $47 \mathrm{kDa}$, and recognized by mAb $6 \mathrm{~A} 3$ in Western blots (Figure 4B) as previously reported in S. lividans cultures [15,24] and in M. tuberculosis secreted proteins $[12,14,48]$. Densitometry analysis of SDS-PAGE shows 3 times higher production of rAPA in coiled and in baffled flasks than in conventional flasks (Figure 4A). Those results correlated with the aggregation morphology, showing higher production in smaller pellets and lower production in the largest ones. Considering that there are no changes in the final biomass concentration, differences in total protein and in rAPA production can be attributed to the morphological variations, most probably caused by the dissimilar culture conditions inside the flasks, i.e. hydrodynamic and oxygen and nutrients transfer conditions.

\section{Analysis of O-mannosylation in rAPA}

$O$-linked glycans at the C-terminal region of rAPA were characterized. rAPA was purified and digested with

Table 1 Morphological differences in cultures carried out in conventional Erlenmeyer normal (NF), baffled (BF), and coiled shake flasks (CF). Data are presented as average \pm standard deviation of image analysis of at least 100 clumps, mycelia or pellets for each sample, and at least 3 samples were analyzed for each flask. Values with the same superscript $(a, b$ or $c)$ are not significantly different by Tukey HSD Test $(p=0.01)$

\begin{tabular}{lcccc}
\hline Shake flask & Area $\left(\mathbf{m m}^{\mathbf{2}}\right)$ & Diameter $(\mathbf{m m})$ & Perimeter $(\mathbf{m m})$ & Roundness $(-)$ \\
\hline Conventional & $2.11 \pm 1.22$ & $1.57 \pm 0.41$ & $6.15 \pm 2.32$ & $1.51 \pm 0.49$ \\
Baffled & $0.04 \pm 0.02^{\mathrm{a}}$ & $0.23 \pm 0.06^{\mathrm{b}}$ & $1.01 \pm 0.35^{\mathrm{c}}$ & $2.11 \pm 0.67$ \\
Coiled & $0.02 \pm 0.01^{\mathrm{a}}$ & $0.16 \pm 0.05^{\mathrm{b}}$ & $0.77 \pm 0.30^{\mathrm{c}}$ & $2.66 \pm 0.98$ \\
\hline
\end{tabular}



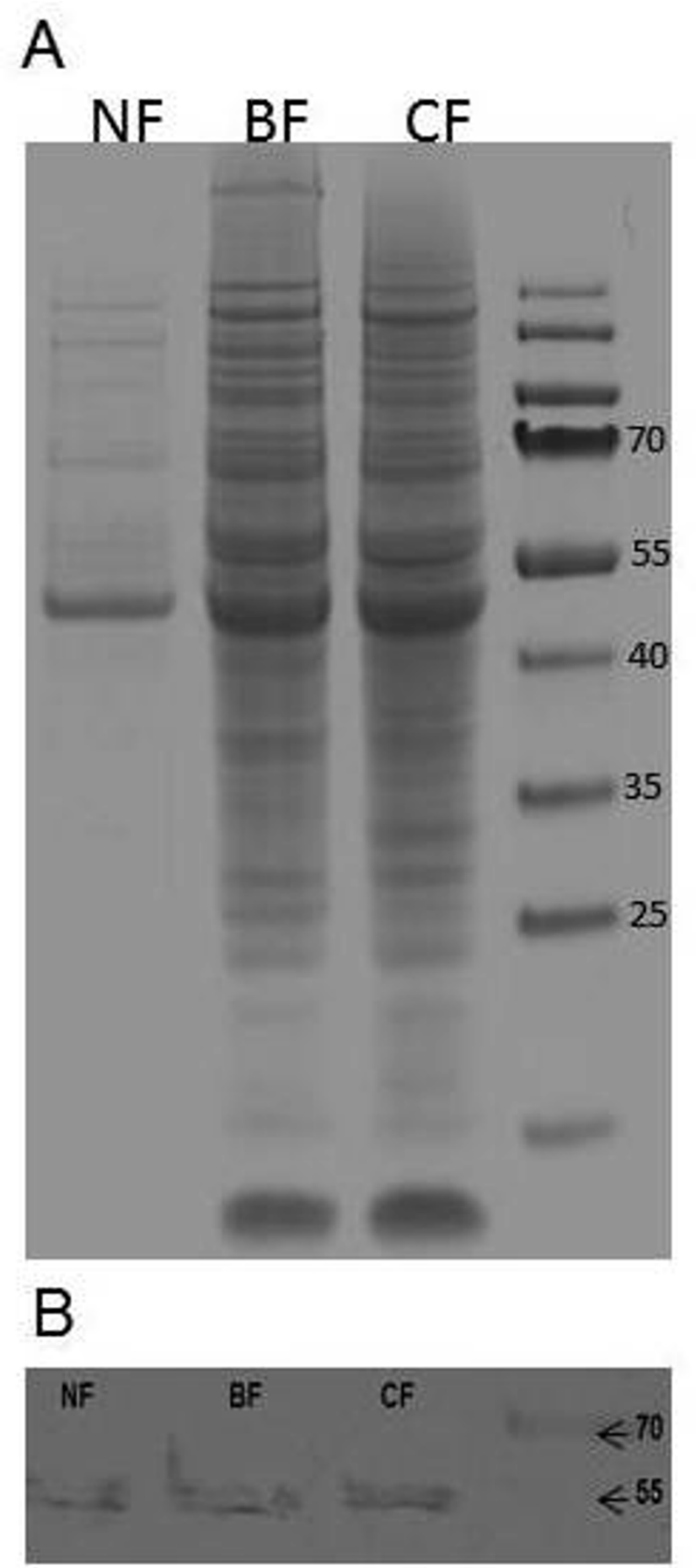

Figure 4 A. SDS-PAGE of total secreted proteins of Conventional Normal (NF), Baffled (BF) and Coiled shake Flasks (CF). B. Western blot of rAPA production by $S$. lividans in the shake flasks used.

LysC, producing at least eight peptides (Table 2). Native APA from $M$. tuberculosis shows in the N-terminal region 0 to 5 mannose residues that correspond to peptide 1 , and in the $\mathrm{C}$-terminal region 0 to 3 mannose residues located in peptide $8[10,11]$. All peptides were analyzed by MALDI-TOF with special focus on P1 and P8. In Figure 5, a typical MALDI-TOF analysis for P8 for each shake flask is shown. In all cases P1 was 
Table 2 Theoretical peptides generated by LysC digestion of rAPA from S. lividans

\begin{tabular}{|c|c|c|c|c|}
\hline Fragment & $\begin{array}{l}\text { Cutting } \\
\text { Position }\end{array}$ & Amino acid sequence & $\begin{array}{l}\text { Peptide } \\
\text { length }\end{array}$ & Mass (Da) \\
\hline P1 & 106 & $\begin{array}{l}\text { DPEPAPPVPTTAASPPSTAA APPAPATPVAPPPPAAANTP NAQPGDPNAAPPPADPNAP } \\
\text { PPVIAPNAPQPVRIDNPVGG FSFALPAGWVESDAAHFDYG SALLSK }\end{array}$ & 106 & 10310.439 \\
\hline P2 & 134 & TTGDPPFPGQPPPVANDTRI VLGRLDQK & 28 & 2987.365 \\
\hline P3 & 145 & LYASAEATDSK & 11 & 1155.227 \\
\hline P4 & 188 & AAARLGSDMGEFYMPYPGTR INQETVSLDANGVSGSASYY EVK & 43 & 4604.056 \\
\hline P5 & 194 & FSDPSK & 6 & 679.728 \\
\hline P6 & 234 & PNGQIWTGVIGSPAANAPDA GPPQRWFVVWLGTANNPVDK & 40 & 4199.698 \\
\hline P7 & 238 & GAAK & 4 & 345.399 \\
\hline P8 & 286 & ALAESIRPLVAPPPAPAPAP AEPAPAPAPAGEVAPTPTTP TPQRTLPA & 48 & 4624.317 \\
\hline
\end{tabular}

detected, but only in its non glycosylated form, since peaks corresponding to the mannosylated P1 peptide could not be clearly detected. In the case of coiled and baffled shake flasks, P8 shows five mannose units attached (Figure 5B, and 5C) with a typical difference between each observed peak of $163 \mathrm{Da}$ corresponding to a single mannose residues. However, in conventional flasks only two mannose units were found attached to the P8 peptide (Figure 5A). In contrast, Lara et al. [15] reported four mannose units in the C-terminal peptide digested by Glu-C in rAPA from S. lividans. However, S. lividans was cultured in $1.0 \mathrm{~L}$ conventional flask (filled with $250 \mathrm{~mL}$ of modified LB medium, 34\% of sucrose). This variation could be due to different shear and/or oxygenation conditions in the $1.0 \mathrm{~L}$ conventional flask if compared with those conditions presented in $250 \mathrm{~mL}$ conventional Erlenmeyer flask.

Data from Figure 5 demonstrate that culture conditions (simulated by three different flasks geometries) can affect the $O$-mannosylation of rAPA produced in S. lividans. At least two different degrees of rAPA $O$-mannosylation can be obtained, but both are different from that reported by Lara et al. [15]. Putting together all the results, it can be assumed that under other culture conditions, other glycoforms might be obtained in S. lividans or in M. tuberculosis, respectively.

Those $O$-mannosylation particularities suggests to play an important function in antigenic roles, because changes in glycosylation patterns of rAPA, produced in different hosts, significantly affect the ability to stimulate $\mathrm{T}$ lymphocytes in vivo $[14,48]$. It will be interesting to evaluate the different $O$-glycoforms produced in the same host (S. lividans), using different culture conditions (either in shake flasks or in bioreactors), and compare them with the native protein immune response.

\section{Conclusions}

The relationship between shear and morphology in filamentous bacteria has been widely studied. In this work, said relationship has been corroborated for S. lividans producing a recombinant glycoprotein. In addition changes in rAPA production and the degree of $O$-glycosylation, both related to morphology, were observed. The different conditions of shear and mass transfer provided by the three shake flask geometries resulted in changes in aggregation morphology. Although, there were significant roundness morphological differences between baffled and coiled shake flasks, but not differences in diameter, said differences were not sufficient to affect the production of rAPA and the degree of $\mathrm{C}$-terminal $\mathrm{O}$-mannosylation. However, the morphology of larger pellets obtained in conventional shake flasks causes a significant decrease in rAPA production and $\mathrm{C}$-terminal peptide $\mathrm{O}$ mannosylation.

To our knowledge, this is the first report indicating how culture conditions can affect the $O$-glycosylation degree in recombinant glycoproteins produced in prokaryotes. Here, a process to obtain at least two different degrees of $O$ mannosylation, using three different flask geometries, was described. A better understanding of how hydrodynamic forces and oxygen/nutrient transfer inside S. lividans aggregates modify the ability to $O$-glycosylate recombinant proteins can be useful in further production processes, with the possibility to manipulate the immunogenic properties. Then, it would be interesting to separately determine and quantify the effect of shear stress and oxygen transfer rates in shake flasks, wherein dissolved oxygen is not controlled, in order to have evidences that can be useful to scale-up the production to a bioreactor.

\section{Methods}

\section{Microorganism and culture conditions}

Wild type S. lividans 66 strain 1326 [32] was transformed with plasmid PIJ6021MT-45 carrying the apa gene under a thiostrepton-inducible promoter, and conferring resistance to kanamycin [15]. A master stock of $30 \mathrm{~mL}$ of spores in $20 \%$ glycerol was obtained, divided into aliquots, and kept at $-20^{\circ} \mathrm{C}$ until use. To start cultures spores were pregerminated in 2XYT medium for $6 \mathrm{~h}$ at $37^{\circ} \mathrm{C}$ and $150 \mathrm{rpm}$ [15]; the germinated spores were then 


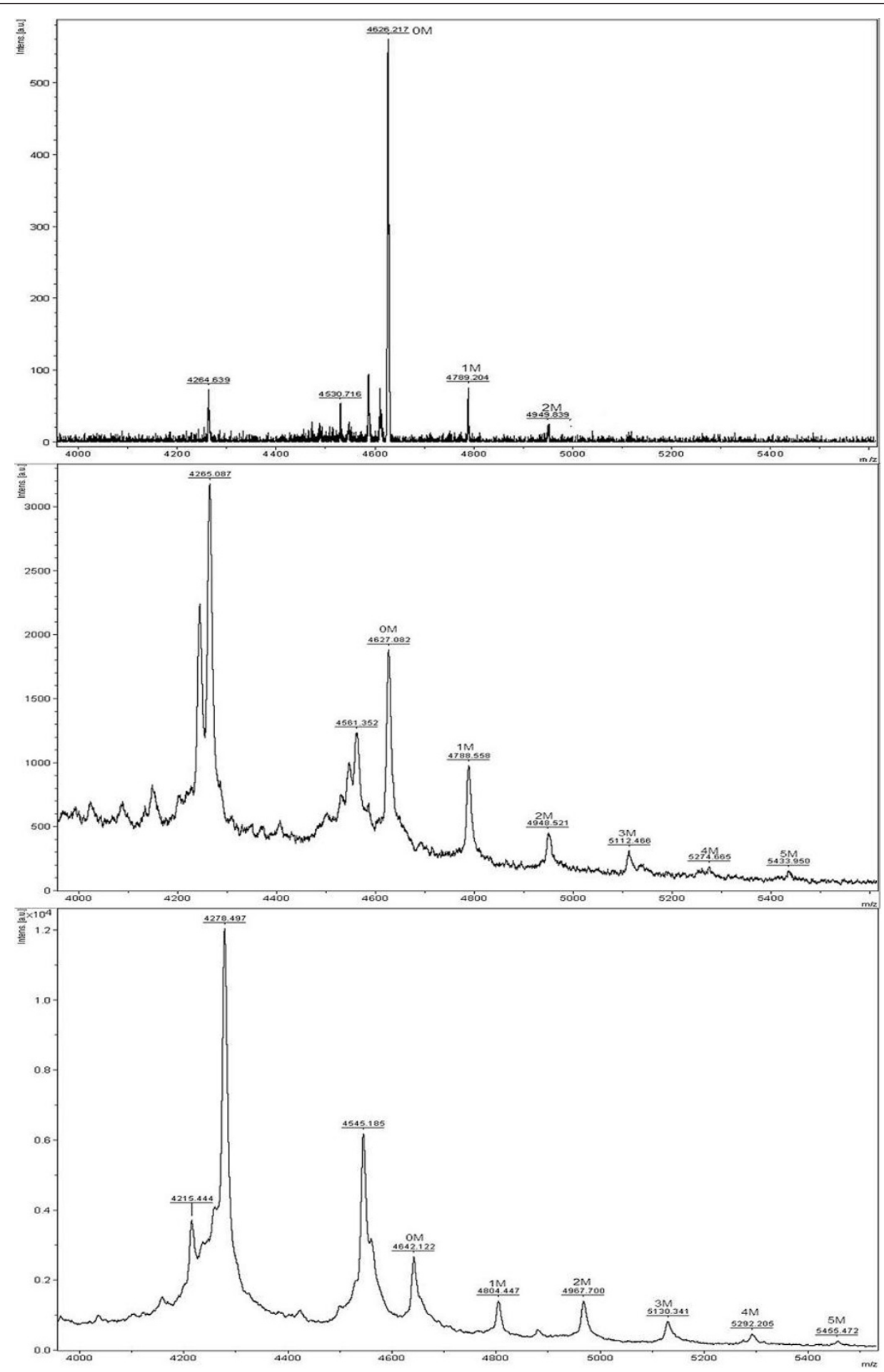

Figure 5 MALDI-TOF analysis for the P8 C-terminal rAPA peptide generated by LysC digestion and obtained in A. Conventional Normal (NF); B. Baffled (BF); and C. Coiled shake Flasks (CF). Numbers above each peak mean the number of mannose units linked to the peptide. At least three MALDI-TOF analyses were done at the end of each independent culture.

washed and sufficient spores were inoculated in order to obtain an optical density of 0.025 at $600 \mathrm{~nm}$ (measured in a Beckman DU730 spectrophotometer). Three different shake flask geometries were tested $(250 \mathrm{ml}$, filled with $50 \mathrm{ml}$ of medium): Coiled Flask (CF), Baffled Flask (BF), and conventional Erlenyemer Normal Flask 
(NF), as is shown in Figure 1. Coiled flasks consist of conventional normal flasks with an inserted $30 \mathrm{~cm}$ stainless steel spring ( $1.3 \mathrm{~cm}$ diameter, $19 \mathrm{sw}$ gauge) as previously described [32]. Culture medium was LuriaBertani's medium with kanamycin $(50 \mu \mathrm{g} / \mathrm{mL})$ modified by addition of $34 \% \mathrm{w} / \mathrm{v}$ sucrose [15]. All cultures were carried out at $30^{\circ} \mathrm{C}$ and $150 \mathrm{rpm}$ for $60 \mathrm{~h}$, with addition of the inducer (thiostrepton $10 \mu \mathrm{g} / \mathrm{mL}$ ) at $16 \mathrm{~h}$ of culture. Two flasks were removed at each kinetic data point for biomass, protein and image analysis.

\section{Analytical determinations}

Biomass was evaluated by dry weight; $10 \mathrm{~mL}$ of culture were filtered through a $0.45 \mu \mathrm{m}$ pore size membrane (Millipore), and washed once with one volume of distilled water. The mycelium obtained was dried for $24 \mathrm{~h}$ in an oven at $55^{\circ} \mathrm{C}$, then placed for $2 \mathrm{~h}$ in a desiccator, and weighed afterwards.

\section{Image analysis procedures}

A sample of $20 \mu \mathrm{L}$ of culture broth was fixed using a formaline solution $(10 \% \mathrm{v} / \mathrm{v})$ in order to avoid the loss of the actual morphology in fresh samples. This sample was placed on a slide, and carefully covered with a cover slip. At least 100 clumps, mycelia or pellets were analyzed for each sample, and at least 3 samples were analyzed for each flask. 2D images were obtained by an image analysis system consisting of a CCD camera (Nikon Color, KP-D50) coupled to a microscope (Nikon Optiphot-2), or a CCD camera (Nikon KP-160) mounted to a stereomicroscope (Olympus SZ40), and a PC with the image analysis software (Image Pro Plus 4.1, Media Cybernetics, Silver Spring, MD) installed in it [49]. The software reported the average diameter and the roundness to characterize the size of aggregates, as the main results. Average diameter is defined as the diameter of a perfect circle, having the same area as the object to be measured. Roundness describes the deviation of mycelial particles from a true circle. In large aggregates (from conventional shake flasks), images were first converted to monochrome and then these grayscale images were processed using a special algorithm for aggregates [50]. One-way ANOVA for independent and samples and pair-wise comparisons using Tukey HSD (Test for Post-ANOVA) were carried out in order to assess the morphological statistical differences between shake flask geometries. Analysis were done using Excel ${ }^{\circledR}$ (2007) and the "VassarStats: Website for Statistical Computation" available on-line of Vassar College, NY-USA (http://faculty.vassar.edu/lowry/anovalu.html).

\section{Purification of rAPA}

All cultures were centrifuged at $10,000 \times g$ and the supernatant was filtered through a $0.45 \mu \mathrm{m}$ membrane (Millipore). Ammonium sulfate was added to the culture filtrate to $75 \%$ saturation and the precipitated proteins were recovered by centrifugation, suspended in PBS (Phosphate Buffered Saline; $10 \mathrm{mM} \mathrm{Na} 2 \mathrm{HPO}_{4}, 2 \mathrm{mM}$ $\mathrm{KH}_{2} \mathrm{PO}_{4}$ ) buffer, dialyzed against distilled water overnight, subsequently against an acetate buffer (Acetic acid 0.2 M, Sodium acetate $0.2 \mathrm{mM}, \mathrm{pH} 5.0$ ) for $24 \mathrm{~h}$, and finally against ConA binding buffer (Sodium acetate $0.1 \mathrm{M}, \mathrm{NaCl} 1.0 \mathrm{M}, \mathrm{Mn}_{2}-4 \mathrm{H}_{2} \mathrm{O} 1 \mathrm{mM}$, Sodium Azide $0.01 \%$ and $\mathrm{CaCl}_{2}-2 \mathrm{H}_{2} \mathrm{O} 1 \mathrm{mM}$ ) for $24 \mathrm{~h}$. The ConAbinding protein $(47-\mathrm{kDa}$ protein) was separated by affinity chromatography on ConA-Sepharose column (Concanavalin A from Canavalia ensiformis, Sigma-Aldrich), and eluted with the ConA binding buffer with $\alpha$ methyl-mannopyranoside $0.05 \mathrm{M}$.

\section{Protein identification and quantification}

Total protein was determined using the Thermo Scientific Pierce BCA Protein Assay Kit (Thermo-Pierce) from supernatant. Electrophoresis in $10 \%$ polyacrylamide gels containing SDS and subsequent immunoblotting procedures were carried out as previously described [15]. For Western blots, $100 \mu \mathrm{g}$ of total protein in SDS-PAGE (10\%) were transferred to polyvinylidine difluoride membranes (Millipore). Nonspecific binding was blocked with $5 \%(\mathrm{w} / \mathrm{v})$ skim milk in PBS containing Tween $20(0.05 \%$ $\mathrm{v} / \mathrm{v}$ ) for one hour. After that, membranes were washed with PBS Tween $0.05 \%$. The primary antibody mAb6A3 was added in dilution 1:500 and incubated overnight at $4^{\circ}$ C [15]. After three washes with PBS-Tween 20, the membranes were incubated with diluted peroxidase-conjugated anti-mouse IgG 1:1000 (Sigma-Aldrich). After incubation, the blots were stained for peroxidase activity by adding 3,3-diaminobenzidine (Sigma-Aldrich) and hydrogen peroxide (Sigma-Aldrich) in PBS and washed with tap water.

\section{Protein digestion}

The 45 and $47 \mathrm{kDa}$ bands were excised and washed with water, distained with ammonium bicarbonate buffer (100 $\mathrm{mM}$ ) with $50 \%$ methanol, dehydrated with acetonitrile (100\%), and rehydrated with ammonium bicarbonate buffer $(25 \mathrm{mM})$ containing enzyme Lys-C (Roche) in dilution 1:1000. Digests were incubated overnight at $37^{\circ} \mathrm{C}, 20 \mu \mathrm{L}$ of Trifluoroacetic acid (TFA, $0.1 \%$ ) were added to stop the reaction, and concentrated in a SpeedVac concentrator (Savant-Thermo) down to a volume of $20 \mu \mathrm{L}$.

\section{MALDI-TOF Analysis}

Masses were determined in a Bruker Microflex matrixassisted laser desorption ionization time-of-flight instrument (Bruker Daltonics GmbH, Leipzig, Germany) equipped with a $20-\mathrm{Hz}$ nitrogen laser at $\mathrm{l}=337 \mathrm{~nm}$. Spectra were recorded in reflector and/or linear positive mode for the mass range of $3800-6000 \mathrm{Da} .1 .0 \mathrm{~mL}$ of 
sample solution was mixed with $5 \mathrm{~mL}$ of $30 \%$ Acetonitrile, $70 \%$ Water, $0.1 \%$ TFA, and saturated with a-cyano4-hydroxycinnamic acid or sinapinic acid. Then, $1.0 \mu \mathrm{L}$ of this solution was deposited onto the MALDI target and allowed to dry at room temperature. At least three MALDI-TOF analyses were done at the end of each independent culture.

\section{Acknowledgements}

This work was partially financed by CONACyT grants 2533, 103214, 103393, and 104951-Z, CONACYT-INNOVAPYME 137854, and PAPIIT-UNAM IN228509-3. RGS thanks the scholarship from CONACyT (316929). Authors thank Celia Flores, M. Sc. and Enrique Galindo, PhD. (Instituto de Biotecnología, UNAM), and Marisol Córdova, PhD. (Centro de Ciencias Aplicadas y Desarrollo Tecnológico, UNAM) for their technical assistance in image analysis. Authors thank Erendida Garcia, Chem. (Instituto de Química, UNAM) for MALDI-TOF analysis. Also, Authors thank Cristina Parada M.Sc. (Instituto de Investigaciones Biomédicas, UNAM) and Prof. J. Büchs group (RWTH Aachen University) for technical assistance on protein purification and quantification. We also thank Ana Delgado for reviewing the English version of the manuscript.

\section{Author details}

'Unidad de Bioprocesos, Instituto de Investigaciones Biomédicas, Universidad Nacional Autónoma de México. AP. 70228, México, D.F., CP. 04510, México. ${ }^{2}$ Departamento de Biología Molecular y Biotecnología, Instituto de Investigaciones Biomédicas, Universidad Nacional Autónoma de México, AP. 70228, México, D.F., CP. 04510, México. ${ }^{3}$ Departamento de Inmunología Instituto de Investigaciones Biomédicas, Universidad Nacional Autónoma de México. AP. 70228, México, D.F., CP. 04510, México.

\section{Authors' contributions}

MATR, NAVC, LSG and CE conceived, supervised and coordinated this study. RAGS participated in the experimental design, carried all cultures. LECD and RAGS carried out the transformations and participated in master stock elaboration. JAMS and RAGS participated in protein purification and identification. RAGS and NAVC carried out the protein digestion and the interpretation of MALDI-TOF analysis. RAGS, MATR and NAVC drafted the manuscript, CE and LSG revised it critically and amended the manuscript. All authors read and approved the final manuscript.

\section{Competing interests}

The authors declare that they have no competing interests.

Received: 6 October 2011 Accepted: 20 December 2011 Published: 20 December 2011

\section{References}

1. Dubrous P, Alaoui H, N'Dounga MB, Koeck JL: Diagnosis of tuberculosis in developing countries: new perspectives. Med Trop (Mars) 2009, 69:618-628.

2. Van DA, Martin A, Palomino JC: Diagnosis of drug-resistant tuberculosis: reliability and rapidity of detection. Int I Tuberc Lung Dis 2010, 14:131-140.

3. Getahun H, Raviglione M: Transforming the global tuberculosis response through effective engagement of civil society organizations: the role of the World Health Organization. Bull World Health Organ 2011, 89:616-618.

4. Espitia C, Servín-González L, Mancilla R: New insights into protein Omannosylation in actinomycetes. Mol Biosyst 2010, 6:775-81.

5. Gonzalez-Zamorano M, Mendoza-Hernandez G, Xolalpa W, Parada C, Vallecillo AJ, Bigi F, Espitia C: Mycobacterium tuberculosis glycoproteomics based on ConA-lectin affinity capture of mannosylated proteins. J Proteome Res 2009, 8:721-733.

6. Torrelles JB, Schlesinger LS: Diversity in Mycobacterium tuberculosis mannosylated cell wall determinants impacts adaptation to the host. Tuberculosis (Edinb) 2010, 90:84-93.
7. Herrmann JL, O'Gaora P, Gallagher A, Thole JE, Young DB: Bacterial glycoproteins: a link between glycosylation and proteolytic cleavage of a $19 \mathrm{kDa}$ antigen from Mycobacterium tuberculosis. EMBO J 1996, 15:3547-3554.

8. Kumar P, Amara RR, Challu VK, Chadda VK, Satchidanandam V: The Apa protein of Mycobacterium tuberculosis stimulates gamma interferonsecreting CD4+ and CD8+ T cells from purified protein derivativepositive individuals and affords protection in a guinea pig model. Infect Immun 2003, 71:1929-1937.

9. Sable SB, Cheruvu M, Nandakumar S, Sharma S, Bandyopadhyay K, Kellar KL, Posey JE, Plikaytis BB, Amara RR, Shinnick TM: Cellular immune responses to nine Mycobacterium tuberculosis vaccine candidates following intranasal vaccination. PLoS One 2011, 6:e22718.

10. Dobos K, Swiderek K, Khoo K, Brennan PJ, Belisle JT: Evidence for glycosylation sites on the 45-Kilodalton glycoprotein of Mycobacteria tuberculosis. Infect Immun 1995, 63:2846-2853.

11. Dobos K, Khoo K, Swiderek K, Brennan P, Belisle J: Definition of the full extent of glycosylation of the 45-kilodalton glycoprotein of Mycobacterium tuberculosis. J Bacteriol 1996, 178:2498-2506.

12. Espitia C, Espinosa R, Saavedra R, Mancilla R, Romain F, Laqueyrerie A, Moreno C: Antigenic and structural similarities between Mycobacterium tuberculosis 50- to 55-kilodalton and Mycobacterium bovis BCG 45- to 47-kilodalton antigens. Infect Immun 1995, 63:580-584.

13. Ragas A, Roussel L, Puzo G, Riviere M: The Mycobacterium tuberculosis cellsurface glycoprotein apa as a potential adhesin to colonize target cells via the innate immune system pulmonary C-type lectin surfactant protein A. J Biol Chem 2007, 282:5133-5142.

14. Horn C, Namane A, Pescher P, Riviere M, Romain F, Puzo G, Barzu O, Marchal G: Decreased capacity of recombinant $45 / 47-k D a$ molecules (Apa) of Mycobacterium tuberculosis to stimulate T lymphocyte responses related to changes in their mannosylation pattern. $J$ Biol Chem 1999, 274:32023-32030

15. Lara M, Servin-Gonzalez L, Singh M, Moreno C, Cohen I, Nimtz M, Espitia C: Expression, secretion, and glycosylation of the $45-$ and $47-\mathrm{kDa}$ glycoprotein of Mycobacterium tuberculosis in Streptomyces lividans. Appl Environ Microbiol 2004, 70:679-685.

16. Aretz W, Koller KP, Riess G: Proteolytic enzymes from recombinant Streptomyces lividans TK24. FEMS Microbiol Lett 1989, 53:31-35.

17. MacLeod AM, Gilkes NR, Escote-Carlson L, Warren RA, Kilburn DG, Miller RC $\mathrm{Jr}$ : Streptomyces lividans glycosylates an exoglucanase (Cex) from Cellulomonas fimi. Gene 1992, 121:143-147.

18. Ong E, Kilburn DG, Miller RC Jr, Warren RA: Streptomyces lividans glycosylates the linker region of a beta-1,4-glycanase from Cellulomonas fimi. J Bacteriol 1994, 176:999-1008.

19. Zirkle $R$, Ligon JM, Molnar I: Heterologous production of the antifungal polyketide antibiotic soraphen A of Sorangium cellulosum So ce26 in Streptomyces lividans. Microbiology 2004, 150:2761-2774.

20. Alduina R, Giardina A, Gallo G, Renzone G, Ferraro C, Contino A, Scaloni A, Donadio S, Puglia AM: Expression in Streptomyces lividans of Nonomuraea genes cloned in an artificial chromosome. Appl Microbiol Biotechnol 2005, 68:656-662.

21. Pimienta E, Ayala JC, Rodriquez C, Ramos A, Van ML, Vallin C, Anne J: Recombinant production of Streptococcus equisimilis streptokinase by Streptomyces lividans. Microb Cell Fact 2007, 6:20.

22. Giardina A, Alduina R, Gottardi E, Di CV, Sussmuth RD, Puglia AM: Two heterologously expressed Planobispora rosea proteins cooperatively induce Streptomyces lividans thiostrepton uptake and storage from the extracellular medium. Microb Cell Fact 2010, 9:44.

23. Scherr N, Nguyen L: Mycobacterium versus Streptomyces-we are different, we are the same. Curr Opin Microbiol 2009, 12:699-707.

24. Vallin C, Ramos A, Pimienta E, Rodriguez C, Hernandez T, Hernandez I, Del SR, Rosabal G, Van ML, Anne J: Streptomyces as host for recombinant production of Mycobacterium tuberculosis proteins. Tuberculosis (Edinb) 2006, 86:198-202.

25. Büchs J: Introduction to advantages and problems of shaken cultures. Biochemical Engineering Journal 2001, 7:91-98.

26. Zimmermann HF, Anderlei T, Buchs J, Binder M: Oxygen limitation is a pitfall during screening for industrial strains. Appl Microbiol Biotechnol 2006, 72:1157-1160. 
27. Gupta A, Rao G: A study of oxygen transfer in shake flasks using a noninvasive oxygen sensor. Biotechnol Bioeng 2003, 84:351-358.

28. Losen M, Frolich B, Pohl M, Buchs J: Effect of oxygen limitation and medium composition on Escherichia coli fermentation in shake-flask cultures. Biotechnol Prog 2004, 20:1062-1068.

29. Büchs J, Maier U, Lotter S, Peter CP: Calculating liquid distribution in shake flasks on rotary shakers at waterlike viscosities. Biochemical Engineering Journal 2007, 34:200-208.

30. Hopwood DA, Bibb MJ, Chater KF, Kieser T, Bruton CJ, Kieser HM, Laydiate DJ, Smith CP, Ward JM, Schrempf H: Genetic Manipulation of Streptomyces. A Laboratory Manual John Innes Institute; 1985.

31. Kieser T, Moss MT, Dale JW, Hopwood DA: Cloning and expression of Mycobacterium bovis BCG DNA in "Streptomyces lividans". J Bacteriol 1986, $168: 72-80$

32. Kieser T, Bibb MJ, Buttner MJ, Chater KF, Hopwood DA: Practical Streptomyces Genetics. John Innes Foundation, Norwich Research Park, Colney, Norwich NR4 7UH, United Kingdom. 2000.

33. Kim MR, Choeng YH, Chi WJ, Kang DK, Hong SK: Heterologous production of streptokinase as a secretary form in Streptomyces lividans and nonsecretary form in Escherichia coli. J Microbiol Biotechnol 2010, 20:132-137.

34. Serrato JA, Palomares LA, Meneses-Acosta A, Ramirez OT: Heterogeneous conditions in dissolved oxygen affect $\mathrm{N}$-glycosylation but not productivity of a monoclonal antibody in hybridoma cultures. Biotechnol Bioeng 2004, 88:176-188, \%20

35. Nam JH, Zhang F, Ermonval M, Linhardt RJ, Sharfstein ST: The effects of culture conditions on the glycosylation of secreted human placental alkaline phosphatase produced in Chinese hamster ovary cells. Biotechnol Bioeng 2008, 100:1178-1192.

36. Gawlitzek M, Estacio M, Furch T, Kiss R: Identification of cell culture conditions to control $\mathrm{N}$-glycosylation site-occupancy of recombinant glycoproteins expressed in CHO cells. Biotechnol Bioeng 2009, 103:1164-1175.

37. Pacis E, Yu M, Autsen J, Bayer R, Li F: Effects of cell culture conditions on antibody N-linked glycosylation-what affects high mannose 5 glycoform. Biotechnol Bioeng 2011

38. Yun Sl, Yahya AR, Malten M, Cossar D, Anderson WA, Scharer JM, MooYoung M: Peptidases affecting recombinant protein production by Streptomyces lividans. Can J Microbiol 2001, 47:1137-1140.

39. Buchs J, Maier U, Milbradt C, Zoels B: Power consumption in shaking flasks on rotary shaking machines: II. Nondimensional description of specific power consumption and flow regimes in unbaffled flasks at elevated liquid viscosity. Biotechnol Bioeng 2000, 68:594-601.

40. Buchs J, Maier U, Milbradt C, Zoels B: Power consumption in shaking flasks on rotary shaking machines: I. Power consumption measurement in unbaffled flasks at low liquid viscosity. Biotechnol Bioeng 2000, 68:589-593.

41. Peter CP, Suzuki Y, Rachinskiy K, Lotter S, Buchs J: Volumetric power consumption in baffled shake flasks. Chemical Engineering Science 2006, 61:3771-3779

42. Maier $\mathrm{U}$, Losen $\mathrm{M}$, Buchs J: Advances in understanding and modeling the gas-liquid mass transfer in shake flasks. Biochemical Engineering Journal 2004, 17:155-167.

43. Nikakhtari H, Hill GA: Closure effects on oxygen transfer and aerobic growth in shake flasks. Biotechnol Bioeng 2006, 95:15-21.

44. Cui YQ, van der Lans RG, Luyben KC: Effects of dissolved oxygen tension and mechanical forces on fungal morphology in submerged fermentation. Biotechnol Bioeng 1998, 57:409-419.

45. Manteca A, Alvarez R, Salazar N, Yague P, Sanchez J: Mycelium differentiation and antibiotic production in submerged cultures of Streptomyces coelicolor. Appl Environ Microbiol 2008, 74:3877-3886.

46. Chang HN, Moo-Young M: Estimation of oxygen penetration depth in immobilized cells. Applied Microbiology and Biotechnology 1988, 29:107-112.

47. Clincke MF, Guedon E, Yen FT, Ogier V, Roitel O, Goergen JL: Effect of surfactant pluronic F-68 on $\mathrm{CHO}$ cell growth, metabolism, production, and glycosylation of human recombinant IFN-gamma in mild operating conditions. Biotechnol Prog 2011, 27:181-190

48. Horn C, Pescher P, Romain F, Marchal G: Characterization of murine monoclonal antibodies specific for the $45 / 47 \mathrm{kDa}$ antigen complex (APA) of Mycobacterium tuberculosis, M. bovis and BCG. J Immunol Methods 1996, 197:151-159.
49. Lucatero S, Larralde-Corona CP, Corkidi G, Galindo E: Oil and air dispersion in a simulated fermentation broth as a function of mycelial morphology. Biotechnol Prog 2003, 19:285-292.

50. Peña C, Reyes C, Larralde-Corona P, Corkidi G, Galindo E: Characterization of Azotobacter vinelandii aggregation in submerged culture by digital image analysis. FEMS Microbiol Lett 2002, 207:173-177.

doi:10.1186/1475-2859-10-110

Cite this article as: Gamboa-Suasnavart et al:: The O-mannosylation and production of recombinant APA (45/47 KDa) protein from Mycobacterium tuberculosis in Streptomyces lividans is affected by culture conditions in shake flasks. Microbial Cell Factories 2011 10:110.

\section{Submit your next manuscript to BioMed Central and take full advantage of:}

- Convenient online submission

- Thorough peer review

- No space constraints or color figure charges

- Immediate publication on acceptance

- Inclusion in PubMed, CAS, Scopus and Google Scholar

- Research which is freely available for redistribution
Ciomed Central 